\title{
SOME FACTORS IN THE PREVENTION OF EQUESTRIAN INJURIES
}

\author{
S. Elizabeth E. ROBSON, SRN
}

\section{Westfield Lane, ROTHLEY, Leicestershire}

I wonder how the average G. P. and family spend their off duty weekends? Are we such an exception or do other such households begin the weekend with an ominous ring on the doorbell and the appearance of a young pony lover clutching a bleeding/broken wrist/nose/ankle? This is no doubt due to the fact that as a family we are interested in sporting injuries and own horses ourselves. A fatal combination for our quiet weekends.

It is very difficult to ascertain the number of injuries that occur with riding, be it for sport or pleasure. An over protected child is likely to present at hospital with comparatively minor trauma but a steeplechase jockey who will certainly attend for a compound fracture of the tibia may well treat his own fractured clavicle with some horse liniment and a nice elastic tail bandage and continue riding.

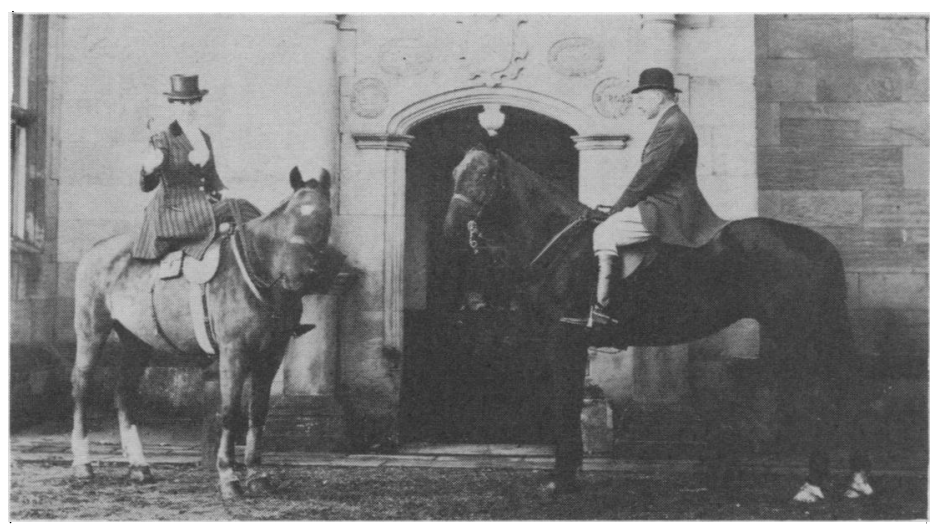

The backward seat.

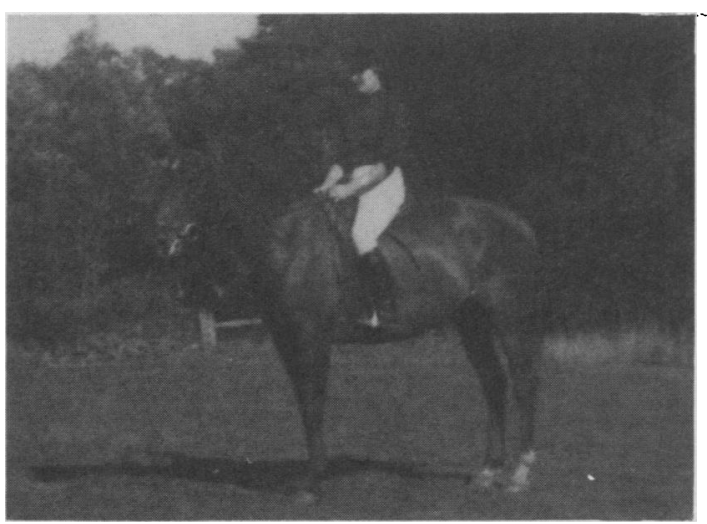

The forward seat.

Riding techniques have changed over the last century and so has the manner in which people injure themselves when riding. Old hunting prints show a very exaggerated backward position when jumping which is quite unlike the modern forward seat seen in the showjumping arena. The backward seat brought most of the rider's weight and centre of gravity over the horse's loins, and the rider's hands had a light contact with the bit. This is a comfortable position for riding long distances but the rider is poorly balanced. A common injury was for the rider, having fallen, to be dragged by the horse with the foot jammed in the stirrup. With the advent of the motor car and the country lanes turning into busy roads a more precise style of riding developed based on that of the flat race jockeys. This new forward seat brings the rider's centre of gravity above that of the horse, which is situated at a point two thirds of the way down the ribcage just behind the withers. There is a firmer contact with the rider's hands and the bit. In this position the stirrups, preferably made out of stainless steel and fitted with rubber treads, should be just below the necks and heads of the metatarsals. Proper footwear must be worn, preferably knee length butcher or short jodhpur boots but failing that boots with an adequate heel. The stirrup should be the correct size for the rider's foot. On no account should plimsolls be worn as they have no heel to prevent the rider's entire foot slipping through and the rider could be suspended at the level of the lower third of the tibia. In such cases not only are fractures and severe bruising likely but severe facial lacerations may be received that will keep the casualty officer out of mischief for a while.

Most injuries occur when the rider is poorly balanced and/or frightened and decides to bail out. There should be no need for the rider to part company with his mount as the average horse is far too sensible to hurt himself. It often takes some time for the novice rider to learn this. The unavoidable injuries are usually due to a horse bucking and rearing or whilst taking large fences at speed e.g. hunting or racing.

Obviously it is preferable that both horse and rider should be physically fit, however this is not always the case. The last time that $I$ saw the editor and his horse departing upon their annual foxhunting expedition last Boxing Day I really wondered which of them was on the largest dose of phenylbutazone. If the rider is fit and mentally alert all the time 
and riding an experienced horse the chances of serious damage are slight unless involved in a road traffic accident or similar misadventure. Many of today's riding accidents involve cars and lorries.

A common sight today is a string of scruffy ponies with sloppy, inattentive riders on their backs meandering all over the road. It often turns out that many such riders have been going once a week to a riding establishment for several years and appear to be none the wiser! Therefore it is reasonable to ask why the standard of riding is so poor amongst the weekend riders. All over the country many moderate sized riding schools that had good teaching standards and turned out many competant riders have had to close down. The reason is that of finance. V.A.T. is gradually ruining the horse trade in this country, and what V.A.T. doesn't do income tax, insurance and running costs certainly will. The small establishments that are now in existance are too often staffed by animal loving teenagers who often prove to be totally incompetant as teachers. Parents and certain types of riding establishments sometimes buy ponies at bargain prices; this usually means that they have only just been broken in and have never been properly schooled. Putting a novice rider on such an animal would be rather like letting a ten year old child drive a TR7 down the M1 on its own.

Another important factor in safe riding is that the rider is correctly dressed. The most important item to have is a hat that has been specially made for riding in this country, i.e. the "hard hat" with a peak over the nose or the more traditional "bowler". It is compulsory for riding schools to insist that children under sixteen years wear hard hats. As
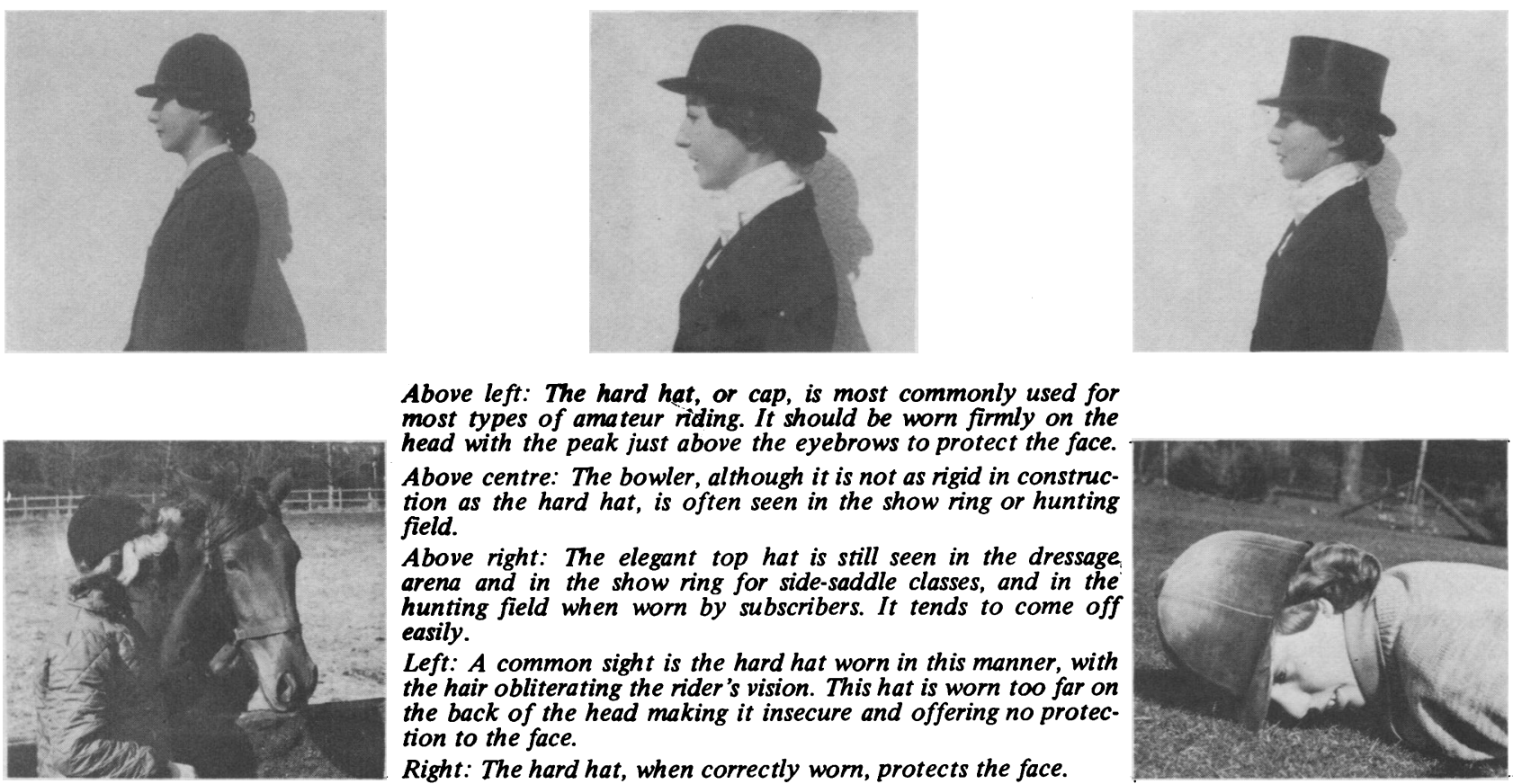

Above left: The hard hat, or cap, is most commonly used for most types of amateur riding. It should be worn firmly on the head with the peak just above the eyebrows to protect the face. Above centre: The bowler, although it is not as rigid in construction as the hard hat, is often seen in the show ring or hunting field.

Above right: The elegant top hat is still seen in the dressage arena and in the show ring for side-saddle classes, and in the hunting field when worn by subscribers. It tends to come off easily.

Left: A common sight is the hard hat worn in this manner, with the hair obliterating the rider's vision. This hat is worn too far on the back of the head making it insecure and offering no protection to the face.

Right: The hard hat, when correctly worn, protects the face.

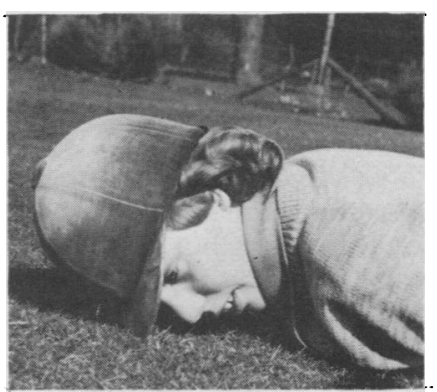

many people do not bother to buy their own they tend to borrow whatever is available in the tack room which may not fit at all. Long hair should always be tied back and secured away from the face either with an elastic band or hairnet, be the rider male or female. If you ever wish to get youself scalped may I suggest that you gallop under a tree branch with your long locks flowing behind you. Another interesting experience for long haired riders is to sit on a shying horse in the middle of the road with a lorry approaching at speed with ones hair blowing across the eyes. This can quite easily result in either the lorry or the horse ending up in the ditch.

Good gloves are essential for colder weather. They are best if made of materials that will help to grip the reins such as string. Woollen gloves are useless when it is raining as the grease from the horse's neck makes the wet leather reins very slippery.

It is nice to own the traditional riding jacket but not essential. A tailored jacket helps to support the back muscles and generally aids good posture. There is good padding around the acromio-clavicular joints, which is very useful when falling from the horse onto the shoulder. 
Again it is nice, but not essential, to wear jodhpurs or breeches that are made out of elasticated material. These are windproof and wrinkle-free and are padded on the inside of the leg, which makes them considerably more comfortable than jeans.

The fashionable trend for many parents at present is to buy various gadgets in the hope of keeping their beloved offspring safe. There are varied arguments about the use of safety stirrups, whose purpose is to prevent the rider from being dragged. In many gymkhanas we have noticed these safety stirrups held in place with baler twine. Are they really of any use?
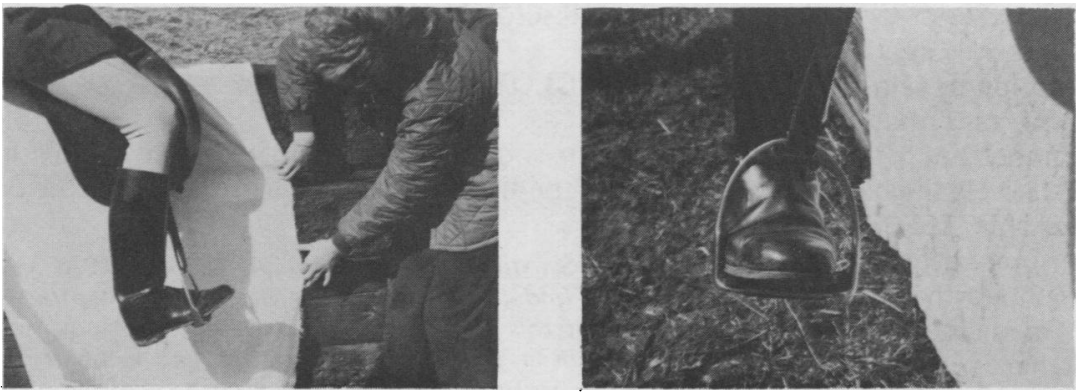

$A$ sensible riding boot and a stirrup of the correct width and height.
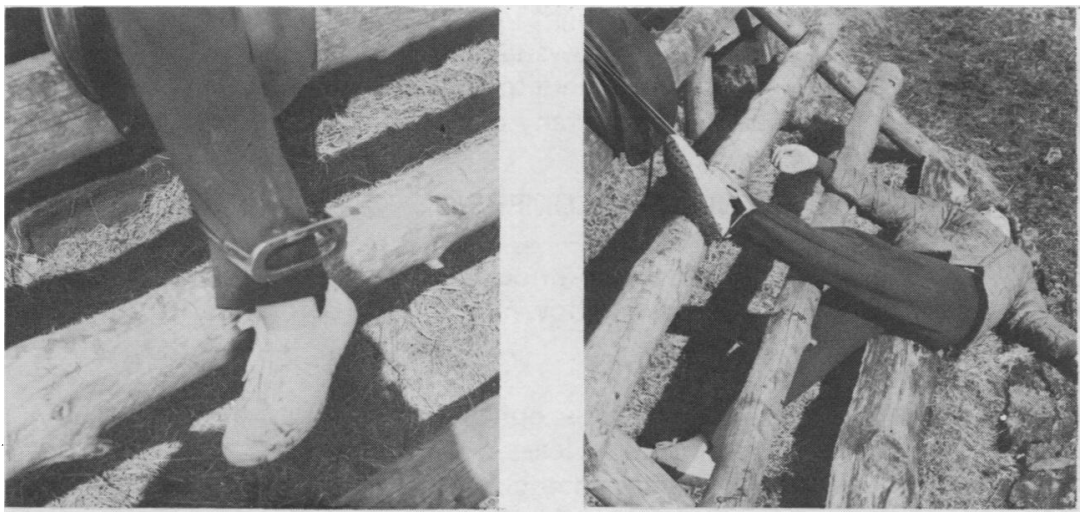

The disadvantage of riding in plimsolls and too large stirrups.

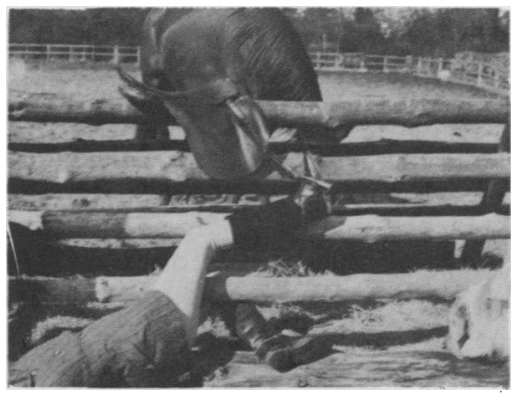

This mock fall shows how this riding boot cannot go through the stirrup. The foot tends to fall from the stirrup as soon as the rider hits the ground.

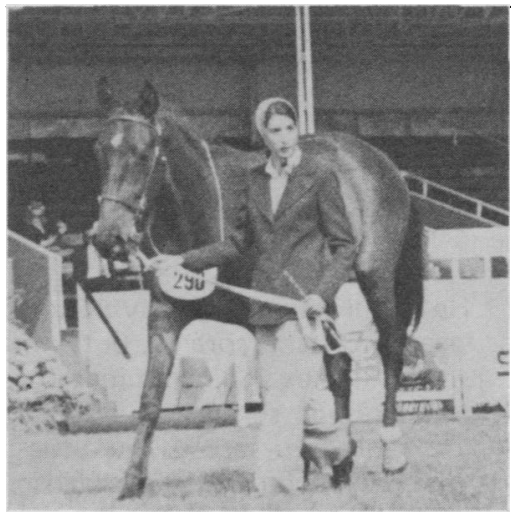

The best way to lead this two year old hunter, with the exhibitor walking beside his shoulder, to avoid being kicked, bitten, reared upon or pushed over.

At the other end of the rider's anatomy the safety harness to hold the hard hat on is often seen - although this seems a good idea I have rarely seen any child keep the harness on for more than half an hour. If the hat fits snugly it shouldn't come off during ordinary riding. Many people feel that if a rider falls on his head it is preferable that once the peak of the hat has borne the impact of the fall the hat should be able to move thus preventing further damage to the nose. For this reason some people prefer to wear a bowler, but they tend to be the more experienced rider. The smaller one's nose, the luckier one is as regards falling off horses.

Finally I should like to point out that one can receive as many injuries coping with horses with both feet firmly on the ground as one can riding them. Therefore it is wise to always be wide awake and careful when dealing with our four footed friends. For the unadventurous who may now have been put off riding for life, may I suggest a nice safe sport. 